\title{
AN UNUSUAL AORTIC ANEURYSM IN AN INFANT
}

\author{
BY \\ A. M. WOMACK and B. WOLMAN \\ From Bury General Hospital
}

(RECEIVED FOR PUBLICATION FEBRUARY 18, 1961)

Aortic aneurysm in infancy is very rare. Excluding examples of aneurysm of the ductus arteriosus in the newborn, we have been able to find only three previously reported cases, all of which were associated with congenital heart disease (Traisman and Johnson, 1953; Hartwell and Ewing, 1954; Rainey and Gilbert, 1958).

This appears to be the first recorded case of aortic aneurysm occurring in infancy as an isolated lesion.

\section{Case Report}

A female infant had been born after a normal delivery on October 10, 1959 with a birth weight of $6 \mathrm{lb} .1 \mathrm{oz}$. The mother had contracted 'influenza' with fever and malaise at the seventh month, but was said to be fully recovered after three weeks, thereafter having a normal confinement. The baby appeared normal after birth and had been fed on artificial milk feeds and made good progress, although she was reported to be a slow feeder.

At the beginning of February 1960, the mother was admitted to another hospital with suspected pneumonia, but was found to have pleural effusion. Her Mantoux test was positive and fluid aspirated from the lung was the typical straw-coloured lymphocytic fluid associated with tuberculous infection, but culture and guinea-pig inoculation gave negative results.

The baby was placed in the care of a foster mother who rushed her to the casualty department on February 17,1960 . The baby had been rather snuffly on the previous day and had suddenly gone pale, started to scream and seemed to have difficulty in breathing.

On admission, she appeared extremely ill, with gasping respiration, marked pallor and a cyanotic tinge to the lips. Her temperature was $99 \cdot 6^{\circ} \mathrm{F}$. and the heart rate was 160 per minute. The heart appeared to be normal in size and there was no audible murmur. Femoral pulses were not palpable. The liver was easily palpable, 2 to $3 \mathrm{~cm}$. below the costal margin. There were basal moist sounds in both lungs but no peripheral oedema.

A tentative diagnosis of congenital heart disease with congestive failure, precipitated by respiratory infection, was made.

Despite treatment with digitalis and penicillin in an oxygen tent, the baby died about three hours after admission.
Autopsy Findings. The body was that of a wellnourished female infant weighing $3,800 \mathrm{~g}$. and showing no external abnormality apart from cyanosis of the extremities.

The abnormal findings were confined to the thoracic cavity.

The pericardium was normal. The heart $(32 \mathrm{~g}$.$) was$ not enlarged and the myocardium appeared normal. The heart valves were normal and there was no endocarditis. The foramen ovale was closed and the ductus arteriosus was obliterated. There were no congenital abnormalities of the heart or great vessels.

In the postero-medial aspect of the upper part of the descending thoracic aorta, a short distance below the obliterated ductus arteriosus, there was an oval hole $8 \mathrm{~mm}$. in diameter, with a smooth, sharply-defined edge (Fig. 1). Through this defect, the aorta communicated with an aneurysmal sac $5 \mathrm{~cm}$. in diameter, the endothelial lining of the vessel appearing to line the first $3-4 \mathrm{~mm}$. of the neck of the sac; otherwise the wall of the sac appeared to be composed of laminated blood clot. The aneurysm occupied the upper part of the posterior mediastinum, compressing the left main bronchus and displacing the oesophagus to the left (Fig. 3). Attached to the intima of the aorta immediately below the oval defect, there was a firm, purplish-red nodule $0.5 \mathrm{~cm}$. in diameter (Fig. 2). The remainder of the aorta was normal and there were no abnormalities in the peripheral vessels.

The anterior aspects of the left upper lobe and right middle lobe were pink and well expanded; otherwise the lungs showed large purple areas of collapse, which were confluent in the left lower lobe.

Histological examination of the aorta revealed no evidence of medial degeneration or loss of elastic tissue, and the only abnormalities were confined to the immediate vicinity of the aneurysm. At the edge of the opening into the aneurysm the muscle and elastic fibres were reflected into the neck of the sac, gradually to merge with and be lost in the organizing blood clot which comprised the major portion of the sac wall. The intimal nodule consisted of cellular fibrous tissue containing a few scattered inflammatory cells, and a few small areas of fibrinoid material (Fig. 4). No microorganisms were seen.

The lungs showed large areas of collapse, with surrounding compensatory emphysema and many of the 


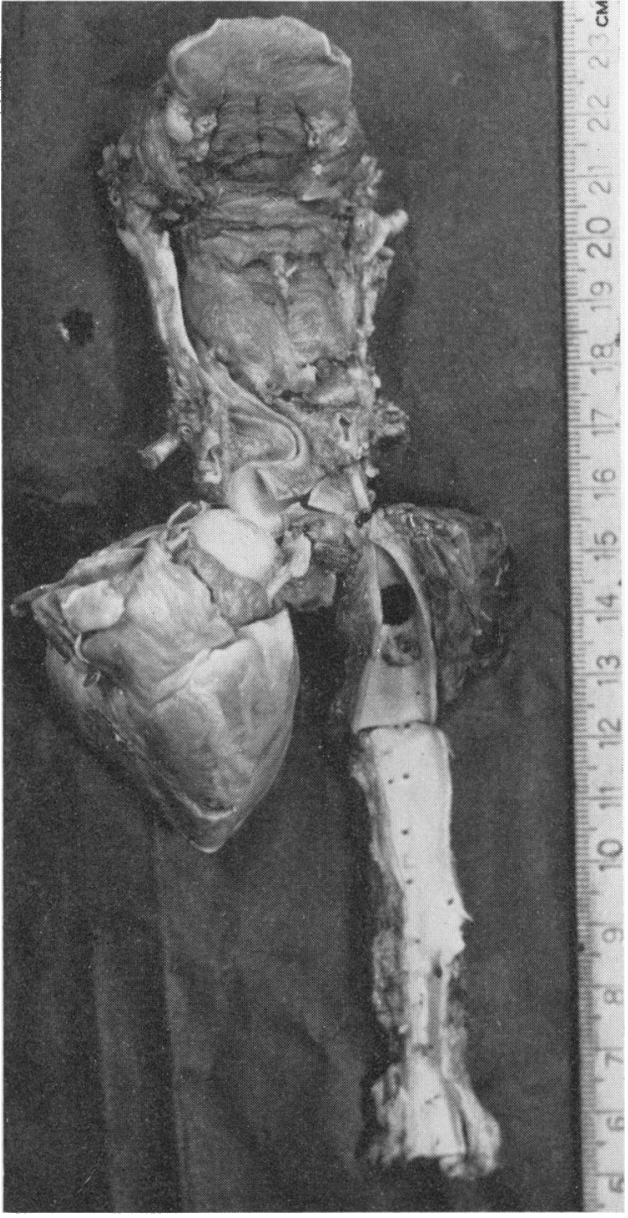

FIG. 1.-Part of the postero-medial aspect of the aneurysm has been removed to allow the specimen to be flat.

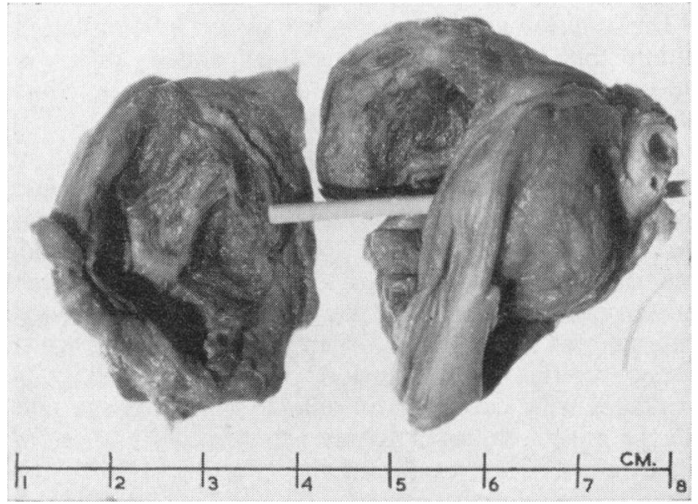

Fig. 3.-Posterior view of the aneurysm with part of the sac wall detached. The probe passes through the neck of the sac into the aorta. Note the stretched oesophagus.

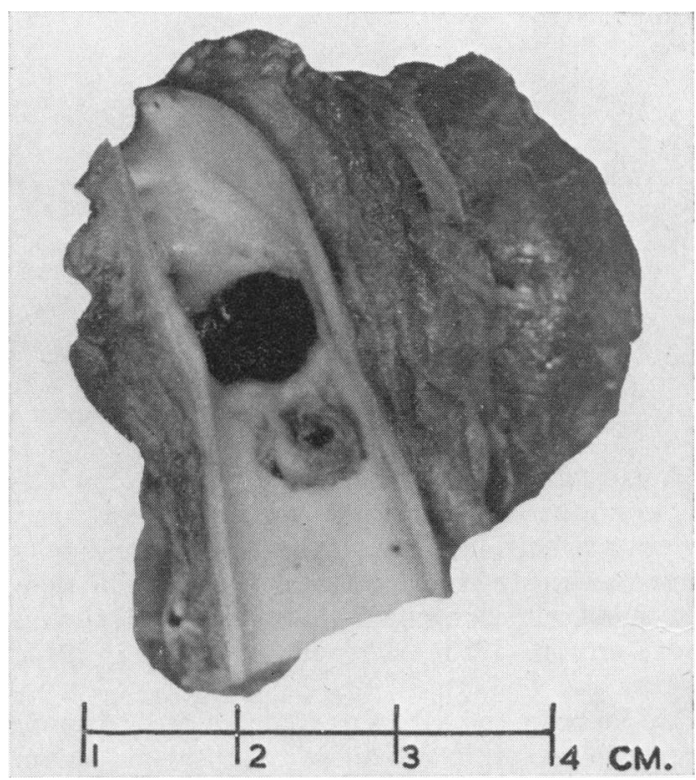

FIG. 2.-Anterior view of the aneurysm with the aorta opened, showing the 'punched out' hole in the aorta and the intimal nodule.

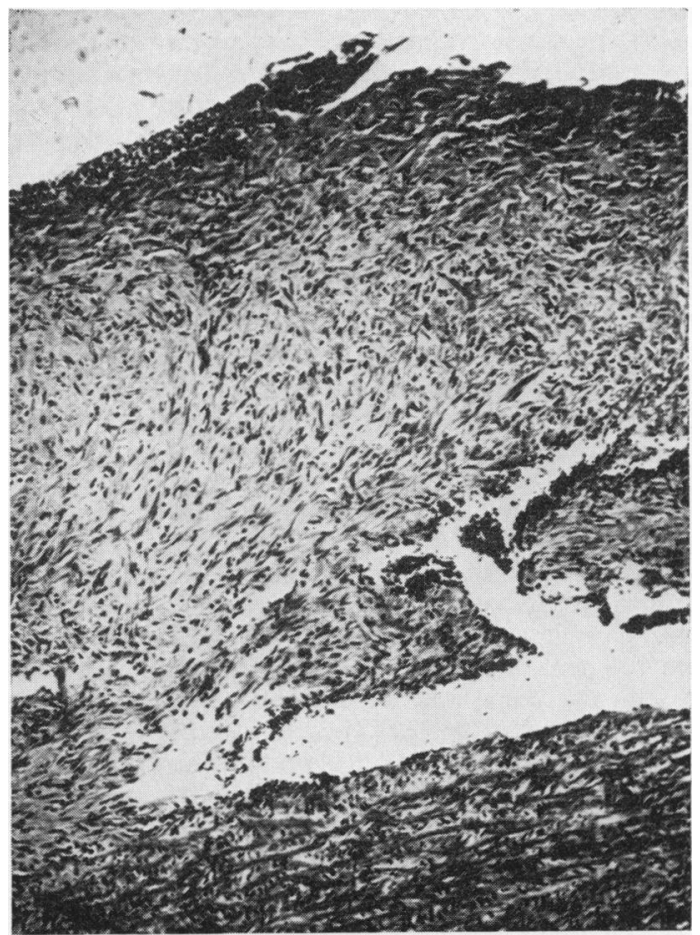

Fig. 4.-Photomicrograph of part of the intimal nodule. (Haemalum and eosin. $\times 38$. ) 
alveoli and smaller bronchi contained inflammatory exudate. These changes were more marked in the lower lobes.

The liver showed slight passive venous congestion and fatty change.

No histological abnormality was seen in sections of myocardium, spleen, kidneys, adrenals and pancreas.

\section{Discussion}

In view of the age of this patient, it would be difficult to avoid the conclusion that this was a congenital aneurysm; but the word 'congenital' in this context does not necessarily denote a developmental abnormality.

Bronson and Sutherland (1918) gave five possible causes of aneurysm in childhood: (1) arteriosclerotic; (2) traumatic; (3) embolic (mycotic); (4) false (due to erosion from without); (5) congenital anomalies; to which list might be added: (6) polyarteritis nodosa.

In our case arteriosclerosis was not present, there was no history of trauma and nothing was found to suggest erosion of the aorta from without. Histological examination showed no evidence of polyarteritis nodosa. This leaves for further consideration two possible aetiological factors, i.e. mycotic and congenital developmental.

Analysis of those cases of congenital developmental aneurysm in which adequate details are given in the literature has revealed several distinctive features. These aneurysms are saccular or fusiform in shape, indicating a relatively large and diffuse weakening of the aortic wall, and are not infrequently associated with dissection. None have shown a relatively small 'punched out' defect as seen in the aorta in this case. Where histological examination of the aorta has been carried out, degenerative changes such as cystic medionecrosis or deficiencies of elastic tissue have been found. Furthermore, in the vast majority of adequately documented cases, congenital heart disease and frequently other congenital developmental anomalies have co-existed, coarctation of the aorta and Marfan's syndrome being among the more commonly associated abnormalities (Bronson and Sutherland, 1918; Calvin and Nichamin, 1934; Baer, Taussig and Oppenheimer, 1943; Schnitker and Bayer, 1944; Petch, 1952; Traisman and Johnson, 1953; Hartwell and Ewing, 1954; Whyte and Lu, 1956; Gulinati and Vita, 1957; Skandalakis, Edwards, Gray, Davis and Hopkins, 1960). Since none of these features existed in the present case, we would be reluctant to presume a congenital developmental aetiology unless the final possibility of a mycotic aneurysm had been excluded.
Only two cases of thoracic aorta aneurysm in children have been reported which structurally resemble that in our patient. Calvin and Nichamin (1934) described a similar aneurysm in a girl of 4 years, which had an oval opening with everted edges $8 \mathrm{~mm}$. below the origin of the left subclavian artery. Near the lower edge of the hole were 'granular deposits', which, on microscopy, were seen to contain gram-positive cocci and diplococci, the diagnosis being 'verrucous streptococcic aortitis'. Javett and Kahn (1952) recorded a case in a child aged 2 years and 7 months in which death occurred after rupture of the aneurysm into a bronchus. This child had first been seen 18 months before death, suffering from non-haemolytic streptococcal septicaemia, at which time the chest radiograph was normal. The descriptions of these two aneurysms indicate a close similarity to the present case, and we consider it to be significant that in both cases there was evidence of a mycotic origin. The photomicrograph of the lesion in the aortic intima of Calvin and Nichamin's case is almost identical with the histological appearances of the nodule present in our case. We believe that it is justifiable to regard this nodule, the presence of which is otherwise difficult to explain, as a vegetation arising on the basis of a previous infective endarteritis.

Following the definition of Crane (1937) each of these aneurysms would be classified as a primary mycotic aneurysm: 'a lesion developing in the wall of an artery which is not associated with any demonstrable intravascular focus, as bacterialendocarditis, or with any in the surrounding tissue'. Such aneurysms are very rare, but published reports emphasize their predilection for the thoracic aorta (Revell, 1945; Javett and Kahn, 1952).

In considering the possibility of a mycotic origin, there remains the problem of the site of the original focus of infection. The infant appears to have thrived from birth, and did not ail at any time before the final fatal illness. It may also be thought that a maximum of four months is too short a time for such a lesion to develop from an infection acquired during extra-uterine life. However, the mother suffered from a febrile illness of three weeks' duration during the seventh month of her pregnancy, and it is not inconceivable that infection could have been transmitted transplacentally to the foetus at that time.

Potter (1952) believes the 'placental barrier' to infection to be greatly overrated and states that bacterial infections can be transmitted readily from mother to foetus, provided bacteraemia is present. In subacute bacterial endocarditis and endarteritis the tendency for infection to lodge where a stream 
of blood impinges on normal endothelial surfaces is well recognized. When infection occurs in ventricular septal defect, the vegetations frequently develop on the wall of the right ventricle, and in patent ductus arteriosus they are most commonly seen at the pulmonary end of the ductus and on the opposite wall of the left pulmonary artery. The portion of the thoracic aorta immediately distal to the opening of the ductus arteriosus would therefore appear to be a favourable site for small infective emboli to become established during intra-uterine life.

\section{Summary}

An aneurysm of the thoracic aorta in a female infant causing death at the age of 4 months is described. The aetiology of the lesion is obscure but it is considered that the balance of evidence is in favour of presuming it to be a congenital mycotic aneurysm.

We wish to thank Miss J. Perry and Mr. R. Chadwick for the photographs.

\section{REFERENCES}

Baer, R. W., Taussig, H. B. and Oppenheimer, E. H. (1943). Congenital aneurysmal dilatation of the aorta associated with arachnodactyly. Bull. Johns Hopk. Hosp., 72, 309.

Bronson, E. and Sutherland, G. A. (1918). Ruptured aortic aneurysms in childhood, with the report of a case. Brit. J. Child. Dis., 15, 241 .

Calvin, J. K. and Nichamin, S. J. (1934). Thoracic aortic aneurysms in children. Their relation to rheumatic fever. Amer. J. Dis. Child., 48, 780.

Crane, A. R.' (1937). Primary multilocular mycotic aneurysm of the aorta. Arch. Path. (Chicago), 24, 634.

Gulinati, G. C. and Vita, G. (1957). Ulteriore contribute alla rottura spontanea dell'aorta. Arcisped S Anna Ferrara, 10, 1371.

Hartwell, A. S. and Ewing, G. M. (1954) Aneurysm of the thoracic aorta in infancy. Postgrad. Med., 16, 546.

Javett, S. N. and Kahn, E. (1952). Rupture of a mycotic aneurysm of the thoracic aorta. Arch. Dis. Childh., 27, 294.

Petch, C. P. (1952). Congenital aortic aneurysm with valvular stenosis and dissecting aneurysm. Brit. Heart J., 14, 147.

Potter, E. L. (1952). Pathology of the Fetus and the Newborn, pp. 105-6. The Year Book Publishers, Chicago.

Rainey, J. R., Jr. and Gilbert, E. F. (1958). Postductal coarctation of the aorta in an infant: case with aneurysms of aortic arch and of the aorta in an infant: case with aneurysms of aortic arch and
anomalies of aortic arch system. Tex. St. J. Med., 54, 735.

Revell, S. T. R., Jr. (1945). Primary mycotic aneurysms. Ann. intern. Med., 22, 431.

Schnitker, M. A. and Bayer, C. A. (1944). Dissecting aneurysm of the aorta in young individuals particularly in association with pregnancy. With report of a case. Ibid., 20, 486.

Skandalakis, J. E. Edwards, B. F., Gray, S. W., Davis, B. M. and Hopkins, W. A. (1960). Coarctation of the aorta with aneurysm Int. Abstr. Surg. 111, 307.

Int. Abstr. Surg., 111, 307.
Traisman, H.S. and Johnson, F. R. (1953). Marfan's syndrome with aortic aneurysm. Amer. J. Dis. Child., 85, 706.

Whyte, D. and Lu, A. T. (1956). Coarctation of the aorta with aneurysm and rupture into the esophagus. Report of a case and review of the literature. J. Pediat., 49, 461. 